\title{
Predictors of Erectile Dysfunction in Type 2 Diabetes Mellitus
}

Ali AM El-Sherbiny.

Public Health and Community Medicine Department, Faculty of Medicine, Tanta University, Egypt

\begin{abstract}
The aim of the study was to determine the frequency of erectile dysfunction among type 2 diabetes (T2DM) milletus and to determine the predictive risk factors of erectile dysfunction in men with T2DM. A cross-sectional study was conducted on 184 men with T2DM from patients attending the internal medicine diabetic outpatient clinic of Tanta university hospital, Gharbia Governorate, Egypt. The results revealed that $42.93 \%$ of study group suffered from erectile dysfunction. Glycated hemoglobin, age in years, systolic and diastolic blood pressure, smoking condition and high total cholesterol are considered significant predictors for erectile dysfunction among T2DM patients. The study concluded that the prevalence of erectile dysfunction was high in men with T2DM and glycated hemoglobin, age in years, systolic and diastolic blood pressure, smoking condition and high total cholesterol are considered significant predictive risk factors for erectile dysfunction among diabetic patients that let us recommend certain measures to prevent, early detection and management of these risk factors.
\end{abstract}

Key words: Predictor, erectile dysfunction, T2DM.

\section{Introduction}

Erectile dysfunction (ED) is described as a persistent inability (more than 6 months) to attain and maintain an erection enough to have a satisfactory sexual performance. ${ }^{(1)} \quad$ Erectile dysfunction (ED) is a common complication in diabetes mellitus (DM). About two fifths to three fourths of diabetic men suffer from ED. ED often occurs $10-15$ years earlier and is more severe among diabetic than non-diabetic men. ${ }^{(2)}$ The causes of diabetic erectile dysfunction in men are complex and involve impairments in blood vessels, muscle, and nerve function. ${ }^{(3)}$ Hyperglycemia may lead to smooth muscle dysfunction by the oxidation of low density lipoprotein and increased production of free-oxygen radical species. ${ }^{(4)}$

ED is associated with a reduced quality of life..$^{(5-8)}$ The overall cost for the treatment of patients suffering from ED in the United States is around 400 million Dollars. ${ }^{(9)}$ Prediction of the risk factors associated with ED in diabetic patients is important for better prevention and management of the disease. So, the aim of the present study was to determine the frequency of ED among type 2 diabetes millets (T2DM) and the predictive risk factors of ED in men with T2DM. 


\section{Materials and Methods}

In this cross-sectional study, all the subjects recruited from men with T2DM were attending the internal medicine diabetic outpatient clinic of Tanta university hospital, Gharbia Governorate, Egypt. Participants gave a written informed consent. The study population consisted of 184 men with T2DM, enrolled between first of January 2013 and the end of May 2013.

\section{Inclusion criteria:}

The inclusion criteria for participation were married men attending the outpatient diabetic clinic with T2DM and aged more than 30 years.

\section{Exclusion criteria:}

The exclusion criteria included patients with major depressive disorder, history of spinal or prostate surgery, and patients with secondary causes of impotency (such as hostility, guilt, anger, or shame). Also, patients had history of hypertension under treatment of beta blockers, $\leq 30$ years of life or unmarried patients were excluded.

\section{Study sample}

The total sample size was calculated using Minitab statistical program version 16 and it was 198 diabetic patients. The minimal sample size for diabetic erectile dysfunction (single proportion) was 180 putting into consideration that comparison probability was $57.0 \%{ }^{(10)}$, hypothesis probability from pretest was $45 \%$ (9 out of 20 diabetic patients) and power of $90.0 \%$. Ten percent were added for dropout cases. The response rate was found to be $92.92 \%$ (184 out of 198). Our study sample constituted 198 type 2 diabetic men $(16.5 \%)$ out of the total study population (1200) diabetic men who attended the diabetic clinic during study period.

\section{Recruitment:}

Recruitment of type 2 diabetic patients was random from daily registered cases (simple random) where every type 2 diabetic patient represented by card with blind selection of one of them. About five cases per day were chosen, two days per week for about five months. Blind selections of other cards were done when the patients were excluded due to exclusion criteria (29 cases; 20 type 1 diabetes, 5 less than 30 years, 3 suffered from hypertension under beta blockers and 1 case suffered from secondary cause of impotence.

\section{Definition of type 2 DM:}

T2DM is defined as noninsulindependent DM or adult-onset diabetes. DM is associated with recurrent or persistent hyperglycemia, and is diagnosed by demonstrating any one of the following: (1) fasting plasma glucose level $\geq 7.0 \mathrm{mmol} 1(126 \mathrm{mg} \mathrm{dl})$; (2) symptoms of hyperglycemia and casual plasma glucose $\geq 11.1 \mathrm{mmol} \mathrm{l}$ (200 $\mathrm{mg} \mathrm{dl}) 2 \mathrm{~h}$ after a $75 \mathrm{~g}$ oral glucose load (post prandial) as in a glucose tolerance test; AND (3) glycated hemoglobin $(\mathrm{HbA} 1 \mathrm{C}) \geq 6.5 \%$.

\section{Definition of erectile dysfunction:}

Erectile dysfunction (ED) is described as a persistent inability (more than 6 months) to attain and maintain an erection sufficient to have satisfactory sexual performance. ${ }^{(1)}$ 
All patients subjected to predesign closed ended questionnaire sheet containing data about biomedical data as age, educational level, smoking status, history of diabetes and weather it juvenile or adult onset, insulin or noninsulin dependent, history of hypertension and if the patient treated with beta blockers or not. Also the questionnaire data included 4 questions related to secondary causes of impotence (anger, hostility, guilt or shame). Patients eligible for inclusion criteria were determined (target group participants).

The target group participants were interviewed face to face using a standardized questionnaire (international index of erectile function (IIEF)-5) ${ }^{(12)}$ to diagnose ED. The questionnaire evaluates five parameters of sexual function including, erectile function, orgasmic function, sexual desire, intercourse satisfaction, and overall satisfaction. Each item was rated on a 5point scale. Thus, a response of 0 for a question was considered the least functional, whereas a response of 5 was considered the most functional. Men with a total score of $\leq 21$ were considered to have ED. The diagnosis was confirmed by internal medicine specialist presented at diabetic clinic.

IIEF-5 questionnaire is the gold standard to quantify erectile dysfunction. A score of 5-7 is regarded as severe; 8- 11 as moderate; 12 - 16 as mild to moderate; $17-21$ as mild and $22-25$ as no erectile dysfunction. ${ }^{(13)}$ Translations of the IIEF have been validated and conducted into several languages including German, and are widely used to evaluate the outcome of pharmacological studies on ED or the outcome of treatment of patients. ${ }^{(14-18)}$
After the interview, the participant's body weight and height was assessed using weight and height scales. The body mass index was calculated by dividing body weight in kilogram by square height in meter where less than 18 was considered underweight, 18 to 25 was considered average, above 25 to less than 30 was considered overweight, 30 to less than 35 was considered mild obese, from 35 to less than 40 was considered as moderate obesity and 40 and above was considered massive obesity. ${ }^{(19)}$ Also, the participant's blood pressure was assessed by using a standard mercury sphygmomanometer after the subject had been seated for at least 5 minutes. Two readings were taken with 5 minutes interval and their mean was recorded. Hypertension was diagnosed when systolic blood pressure $\geq 140 \mathrm{mmHg}$ and diastolic blood pressure $\geq 90 \mathrm{mmHg}$. ${ }^{(20)}$

For biochemical investigations, a venous blood sample was taken (throughout clinical pathology department of Tanta university hospital) in the morning after a twelve hours fasting for the determination of total cholesterol, highdensity lipoprotein concentrations (HDL), fasting blood sugar and HbA1C. Dyslipidemia was diagnosed when total cholesterol level was more than 200 $\mathrm{mg} / \mathrm{dl}$, and high- density lipoprotein was less than $40 \mathrm{mg} / \mathrm{dL}$ in men. ${ }^{(21)}$ Diabetes mellitus was diagnosed when fasting blood glucose level $\geq 126 \mathrm{mg} / \mathrm{dl}$. ${ }^{(19)}$ HbA1c percentage was determined by ion-exchange method. An HbAlc of $6.5 \%$ is recommended as the cut off point for diagnosing diabetes. (22) All measurements were made under standard conditions by one technician and with the same device. 


\section{Data Analysis}

All questionnaires were coded and entered into an electronic database. Data analysis was carried out using Statistical Package for Social Sciences (SPSS) version 20. Frequency of distributions with numbers and percentages as well as mean and standard deviation for qualitative and quantitative data respectively of all variables produced. Risk analysis were done using odds ratio for study independent variables in relation with diabetic patients suffered from erectile dysfunction and patients with normal erectile function. The independent variables considered were age, educational level, smoking condition, physical activity, body mass index, systolic and diastolic blood pressure, fasting blood sugar, high density lipoprotein, total serum cholesterol and glycated hemoglobin (HbA1C). Multivariate analysis was done using stepwise linear regression analysis for erectile function score with all independent variables. Linear correlation was done between erectile function score and other independent variables.

\section{Ethical Considerations}

Verbal consent was taken from all participants in line with the Ethics protocol of medical research. Raw data treated with strict confidentiality and used only for research purposes.

\section{Results}

The majority $(64.1 \%)$ of our target group were aged more than 50 years old and low educated (illiterate and literate) constituted $63.6 \%$. About two thirds of the participants were overweight \& obese and most of them (88.6\%) not practiced any type of sport respectively. On the other hand, $10.3 \%, 33.7 \%, 20.2$ and $6 \%$ of our sample were cigarette smokers, hypertensive, hypercholesterolemic and had low level of HDL respectively (table1).

The mean age of our study group was $50.25 \pm 9.44$ years. The mean systolic blood pressure was found to be $129.37 \pm$ $14.71 \mathrm{mmHg}$ and mean diastolic blood pressure was $84.37 \pm 9.83 \mathrm{mmHg}$. The mean fasting blood sugar, total cholesterol, HDL and $\mathrm{Hb}$ A1C found to be $167.93 \pm 28.53 \mathrm{mg} / \mathrm{dL}, 205.89 \pm$ $42.49,48.88 \pm 7.71 \mathrm{mg} / \mathrm{dL}$ and $7.68 \pm$ $1.06 \mathrm{mg} / \mathrm{dL}$ respectively. On the other hand, the mean erectile function score was found to be $19.47 \pm 5.99$ with range between 7 and 25 (table 1).

All diabetic patients aged $\leq 50$ years had normal erectile function while $66.9 \%$ of patients more than 50 years suffered from erectile dysfunction and the association was statistically significant. On the other hand, educational level had non-significant risk for erectile dysfunction $(\mathrm{p}>0.05 \&$ odds ratio $=$ 0.569). $89.5 \%$ of smokers had erectile dysfunction with statistically significant risk compared to $37.6 \%$ among nonsmokers $(p<0.05 \&$ odds ratio $=14.12)$. Overweight and obese patients suffered from higher frequency of erectile dysfunction $(63.1 \%)$ than patients with average body weight (3.2\%) with significant odds of $51.33 \quad(\mathrm{p}<0.05)$. Hypertensive patients suffered from higher frequency of erectile dysfunction $(96.8 \%)$ than normotensive patients $(15.6 \%)$ with significant odds of 162.63 $(\mathrm{p}<0.05)$. Patient suffered from hypercholesterolemia suffered from higher frequency of erectile dysfunction $(97.3 \%)$ than patients with normal total 
serum cholesterol level (29.3\%) with significant odds of $87.07 \quad(\mathrm{p}<0.05)$. Patient suffered from lower HDL suffered from higher frequency of erectile dysfunction (72.7\%) than patients with normal HDL level $(41.0 \%)$ with in-significant odds ratio of 3.83 (p>0.05) (table 2).

Table (3) revealed that high glycated hemoglobin (HbA1C), old age, high blood pressure, smoking condition and high total cholesterol were considered significant predictors for erectile dysfunction among diabetic patients while educational levels, body mass index, fasting blood sugar level, HDL and sport practice were excluded variables. Glycosylated hemoglobin effect was found to be the most effective predictors for erectile dysfunction among diabetic patients with overall effect of $97.3 \%$ for all significant predictors.

Table (4) revealed a significant negative correlation between erectile function score from one side and systolic blood pressure, diastolic blood pressure, total serum cholesterol, and age in years from the other side while significant positive correlation was found with HDL. There was no significant correlation between erectile function score and fasting blood sugar.

Our study revealed that $42.93 \%$ of study group suffered from erectile dysfunction. Severe, moderate, mild to moderate and mild erectile dysfunction constituted $6.34 \%, 48.10 \%, 43.03 \%$ and $2.53 \%$ respectively (figure $1 \& 2$ ).

\section{Discussion}

The prevalence of erectile dysfunction among diabetic men varies between 35 and $90 \%$. ${ }^{(23)}$ Erectile dysfunction was detected in over $50 \%$ of men with diabetes in the U.S and in $41 \%$ of diabetic men in the Netherlands. ${ }^{(24 \& 25)}$ Studies from Saudi diabetic patients reported ED among 80 to $90 \%$ of the patients. ${ }^{(26 \& 27)}$ Sexual dysfunction was detected in $77 \%$ of diabetic men in Isfahan province of Iran. ${ }^{(28)}$

The majority of our target group aged more than 50 years, low educated (illiterate and literate), overweight \& obese and not practiced any type of sport respectively. On the other hand, $10.3 \%$, $33.7 \%, 20.2$ and $6 \%$ of our sample were cigarette smokers, hypertensive, hypercholesterolemic and had low level of HDL respectively (table1). Niciane et al., (2013) found nearly the same results. (29) In the Framingham Heart Study, 13\% of men with diabetes mellitus had increased total plasma cholesterol levels. Also the study found that the prevalence of high LDL cholesterol levels in men with diabetes mellitus was $9 \% .{ }^{(30)}$ The previous results may explained based that low level of education lead to unsound eating behavior as well as unsound life style related to physical inactivity which lead to obesity, hypertension, hypercholesterolemia and diabetes.

The mean age of study group was 50.25 \pm 9.44 years. Similar study by Romeo et al., (2000) found that the mean age for diabetic subjects was $62.0 \pm 12.3$ years. (25) The difference between our results and Romeo et al study may be due to difference of socioeconomic level and life style. The mean fasting blood sugar, total cholesterol and HDL found to be 
$167.93 \pm 28.53 \mathrm{mg} / \mathrm{dL}, 205.89 \pm 42.49$ and $48.88 \pm 7.71 \mathrm{mg} / \mathrm{dL}$ respectively. The mean level of $\mathrm{HbA1C}$ in our study was $7.68 \pm 1.06$ and the mean erectile function score was $19.47 \pm 5.99$ in our study. Romeo et al., (2000) found the mean $\mathrm{HA} 1 \mathrm{C}$ was $8.1 \% \pm 1.9 \%$ and mean erectile function score was $16.6 \pm 5.9$ (range 5 to 23). ${ }^{(31)}$ The results of our study indicate uncontrolled diabetes and associated hypercholesterolemia according to their definition. ${ }^{(19,21,22)}$ the difference between our study results regarding erectile score and other study was attributed to difference in socioeconomic profile, life style and associated risk factors.

All diabetic patients age $\leq 50$ years had normal erectile function while $66.9 \%$ of patients more than 50 years suffered from erectile dysfunction with statistical significant difference between normal and erectile dysfunction according to age (table 3). Fonseca et al., (2004) found higher percentages of men in age groups of 50-59 years than those from 60-69 years, suffering from severe ED; indicated that severity increased with advancing age $(\mathrm{p}=0.007){ }^{(32)}$ Our study revealed that patient suffered from overweight and obesity suffered from higher frequency of erectile dysfunction (63.1\%) than patients with average body weight (3.2\%) with significant odds ratio of 51.33. However, Fonseca et al., (2004) found that BMI did not influence the occurrence of erectile function. ${ }^{(32)}$

The present study found that most of smokers had erectile dysfunction with statistically significant risk compared to nonsmokers $(41.5 \%)$ (odds ratio = 1.56). Similarly, Fedele et al, in Italy, have established an association between tobacco smokers and occurrence of erectile dysfunction. They found that smoking potentiates the effects of chronic conditions favoring the development of endothelial dysfunction. ${ }^{(33)}$

Patient suffering from hypertension had higher frequency of erectile dysfunction (96.8\%) than normotensives (15.6\%) with significant odds ratio of 162.63 . Martin-Morales et al., (2001) demonstrated that high blood pressure (odds ratio $=1.58$ ), tobacco use (odds ratio $=2.5$ ) were significantly associated with erectile dysfunction. ${ }^{(34)}$ Also, Arvind et al., (2013) found that $57.1 \%$ of the subjects with severe ED had associated Hypertension, whereas about $36.7 \%$ subjects with no ED had hypertension. ${ }^{(35)}$

Patient suffering from hypercholesterolemia had higher frequency of erectile dysfunction (97.3\%) than patients with normal total serum cholesterol level (29.3\%) with significant odds ratio of 87.07. Patient suffering from lower HDL had higher frequency of erectile dysfunction (72.7\%) than patients with normal HDL level $(41.0 \%)$ with in-significant odds ratio of 3.83 (table 3 ). The same result attained by Fedele et al., (2000) in Italy. He explained this association due to the occurrence of endothelial dysfunction in hyperlipidemia. ${ }^{(33)}$ Some studies demonstrated that erectile function was significantly damaged in hyperlipidemic conditions because of some structural change of penile vessels. ${ }^{(36 \& 37)}$

\section{Predictors of ED among T2DM:}

Stepwise linear regression analysis demonstrated that glycated hemoglobin, old age, high blood pressure, current cigarette smoking and high total 
cholesterol were considered significant predictors for erectile dysfunction among diabetic patients. Glycosylated hemoglobin effect found to be the most prominent predictors for erectile dysfunction among diabetic patients. Romeo et al., (2000) found through Multivariate analysis that $\mathrm{HbA} 1 \mathrm{C}$ was an independent predictor of erectile function score $(\mathrm{p}<0.001){ }^{(31)}$

Our study revealed that more than two fifths of study group suffered from erectile dysfunction. Among our study group, severe, moderate, mild to moderate and mild erectile dysfunction constituted $6.34 \%, 48.10 \%, 43.03 \%$ and $2.53 \%$ respectively. In Pakistan, Ahmed et al., (2013) found that only $28 \%$ of diabetic patients was not suffered from erectile dysfunction while $17.1 \%$, $37.8 \%, 21.7 \%$ and $20.7 \%$ had mild, mild to moderate; moderate; and severe erectile dysfunction respectively. (38) Giugliano et al., (2010) found that about $60 \%$ of diabetic men had varying degrees of erectile dysfunction (mild $9 \%$, mild to moderate $11.2 \%$, moderate $16.9 \%$ and severe $22.9 \%)^{(39)}$

There were significant negative correlations between erectile function score from one side and systolic blood pressure, diastolic blood pressure, total serum cholesterol, and age in years from the other side while significant positive correlation was found with HDL. There was no significant correlation between erectile function score and fasting blood sugar (table 5). A negative significant correlation found between potency score and $\mathrm{HbA} 1 \mathrm{c}$, fasting blood glucose (FPG) and systolic blood pressure (SBP) but not between other risk factors such as lipid profile and BMI. ${ }^{(40)}$ There was a direct correlation between degrees of glycemic control status, as was assessed by $\mathrm{HbA} 1 \mathrm{c}$ and degree of ED which were assessed by IIEF-5. ${ }^{(35)}$

\section{Limitations of the study}

In spite of the study excluded patients with secondary causes of impotency (such as hostility, guilt, anger, or shame); it is still in need for in-depth study related to psychological risk factors of ED as it is not enough to ask about sensations.

\section{Conclusion}

In conclusion, we found that ED prevalence was high in men with T2DM compared with non-diabetics (from literature). Abnormal high glycated hemoglobin, old age, hypertensive, cigarettes smokers and high total cholesterol are considered significant predictive risk factors for erectile dysfunction among diabetic patients that let us to recommend a certain measures to prevent and early detection and management of these risk factors.

\section{References}

1) NIH consensus conference: Impotence. NIH consensus development panel on impotence. Journal of the American Medical Association, 1993, 270: 8390.

2) Malavige LS, Levy JC.: Erectile dysfunction in diabetes mellitus. J Sex Med., 2009, 6: 1232-1247. 
3) Thorve VS, Kshirsagar AD, Vyawahare NS, Joshi VS, Ingale KG, et al.: Diabetes-induced erectile dysfunction: epidemiology, pathophysiology and management. J Diabetes Complications, 2011, 25: 129-136.

4) Long T, Liu G, Wang Y, Chen Y, Zhang $\mathbf{Y}$ and et al.: TNF-alpha, erectile dysfunction, and $\mathrm{NADPH}$ oxidase-mediated ROS generation in corpus cavernosum in high-fat diet/streptozotocin-induced diabetic rats. J Sex Med., 2012, 9: 1801-1814.

5) Yang G, Pan C, and Lu J.: Prevalence of erectile dysfunction among Chinese men with type 2 diabetes mellitus. International Journal of Impotence Research, 2010, 22, (5): 310317.

6) CC Lu.: Smoking habits and erectile dysfunction in type 2 diabetic patients. Journal of Sexual Medicine, 2010, 7 (4): 1593-1593.

7) LS Malavige and JC Levy: Erectile dysfunction in diabetes mellitus. Journal of Sexual Medicine, 2009, 6 (5): 1232-1247.

8) H Sasaki, H Yamasaki, K Ogawa and et al.: Prevalence and risk factors for erectile dysfunction in Japanese diabetics," Diabetes Research and Clinical Practice, 2005, 70 (1): 8189.

9) CS Saigal, H Wessells, J Pace, M Schonlau, and TJB Wilt: Predictors and prevalence of erectile dysfunction in a racially diverse population. Archives of Internal Medicine, 2006, 166 (2): 207-212.

10) P. Costa, T Grivel, F Giuliano, P Pinton, E Amar and A Lemaire: La Dysfonction Erectile: Un Symptôme Sentinelle?. Progrès en Urologie, 2005, 14: 203-207.
11) WHO.: Definition and diagnosis of diabetes mellitus and intermediate hyperglycemia (pdf). World Health Organization www.who.int2006,http://w hqlibdoc.who.int/publications/2006/9241 594934_eng.pdf.

12) RC Rosen, JC Cappellen, $N$ Gerdrano: The International Index of the Erectile Function (IIEF): a state of the science review, International Journal of Impotence research: 2002;14:226 244.

13) RC Rosen, A Riley, G Wagner, IH Osterloh, J Kirkpatrick, and A Mishra: The international index of erectile function (IIEF): a multidimensional scale for assessment of erectile dysfunction/ Urology, 1997, 49 (6) 822-830.

14) Glinda $S$ et al.: International Index of Erectile Function (IIEF): is it an universal tool? J Urol., 2001, 165 (Suppl): 272.

15) Quek KF et al.: Reliability and validity of the Malay version of the International Index of Erectile Function (IIEF-15) in the Malaysian population. Int J Impot Res., 2002, 14: 310-315.

16) Althof SE.: Quality of life and erectile dysfunction. Urology, 2002, 59: 803-810.

17) Lebret $\mathbf{T}$ et al.: Extracorporeal shock wave therapy in the treatment of Peyronie's disease: experience with standard lithotriptor (SiemensMultiline). Urology, 2002, 59: 657-661. 18) Cavallini G, Biaggiotti G, Koverech A and Itali G.: Oral propionyl-L-carnitine and intraplaque verapamil in the therapy of advanced and resistant Peyronie's disease. BJU Int., 2002, 89: 895-900.

19) Namayandeh SM, Sadr SM, Ansari $Z$ and Rafiei M.: A Crosssectional study of the prevalence of 
coronary artery disease traditional risk factors in Yazd urban population, Yazd healthy heart project. Iran. Cardiovasc. Res. J., 2011, 5(1): 7-13.

20) Kuklina EV, Yoon $P W$ and Keenan NL.: Prevalence of coronary heart disease risk factors and screening for high cholesterol levels among young adults, United States, 1999-2006. Ann. Fam. Med., 2010, 8(4): 327-333.

21) Capingana DP, Magalhães $P$, Silva ABT, Gonçalves MAA, Marcelo MP, Rodrigues SL, Simões CCF, VL Ferreira AVL and Mill JG.: Prevalence of cardiovascular risk factors and socioeconomic level among publicsector workers in Angola. BMC Public Health, 2013, 13:732

22) WHO.: Use of Glycated Haemoglobin (HbA1c) in the Diagnosis of Diabetes Mellitus, Abbreviated Report of a WHO Consultation. 2011, http://www.who.int/diabetes/publication s/report-hba1c_2011.pdf

23) Grover SA, Lowensteyn I, Kaouache $M$ and et al.: The prevalence of erectile dysfunction in the primary care setting: importance of risk factors for diabetes and vascular disease. Archives of Internal Medicine, 2006, 166 (2): 213-219.

24) Selvin E, Burnett AL, and Platz EA.: Prevalence and risk factors for erectile dysfunction in the US,"American Journal of Medicine, 2007, 120 (2): 151-157.

25) Cleveringa FGW, Meulenberg MGG, Gorter KJ, van den Donk M, and Rutten GEHM.: The association between erectile dysfunction and cardiovascular risk in men with Type 2 diabetes in primary care: it is a matter of age," Journal of Diabetes and its Complications, 2009, 23 (3): 153-159.
26) El-Sakka I.: Characteristics of erectile dysfunction in Saudi patients. International Journal of Impotence Research, 2004, 16 (1): 13-20.

27) I. El-Sakka and K. A. Tayeb: Erectile dysfunction risk factors in noninsulin dependent diabetic Saudi patients. Journal of Urology, 2003, 169 (3): 1043-1047.

28) Ziaei-Rad M, Vahdaninia $M$, and Montazeri A.: Sexual dysfunctions in patients with diabetes: a study from Iran. Reproductive Biology and Endocrinology, 2010, 8: 50.

29) Marinho NBP, de Vasconcelos HCA, Alencar AMPG, de Almeida PC and Damasceno MMC.: Risk for type 2 diabetes mellitus and associated factors Acta paul. enferm., 2013, 26: 6. São Paulo Nov./Dec.

http://www.scielo.br/scielo.php?pid=S01 03

21002013000600010\&script=sci_arttext \&tlng=en\#end

30) Kannel WB.: Lipids, diabetes, and coronary heart disease: insights from the Framingham Study. Am Heart J., 1985, 110: 1100-1107.

31) Romeo JH, Seftel AD, Madhun ZT and Aron DC.: Sexual function in men with diabetes type 2: association with glycemic control. J Urol., 2000, 163(3): 788-91.

32) Fonseca V, Seftel A, Denne J and Fredlund P.: Impact of Diabetes Mellitus on the Severity of Erectile Dysfunction and Response to Treatment: Analysis of Data from Tadalafil Clinical Trials," Diabetologia, 2004, 47 (11): 1914-1923.

33) Fedele D, Bortolotti A, Coscelli C, Santeusanio F, Chatenoud L, Colli E, Lavezzari $M$, Landoni $M$ and Parazzini F.: Erectile Dysfunction in Type 1 and Type 2 Diabetics in Italy. 
International Journal of Epidemiology, 2000, 29 (3): 524-531.

34) Martin-Morales A, Sanchez-Cruz JJ, Saenz de Tejada I, Rodriguez-Vela L, Jimenez-Cruz JF and BurgosRodriguez R.: Prevalence and independent risk factors for erectile dysfunction in Spain: results of the Epidemiologia de la Disfuncion Erectil Masculina Study. J Urol., 2001, 166 (2):569-74.

35) Goyal A, Singh P, and Ahuja A.: Prevalence and Severity of Erectile Dysfunction as Assessed by IIEF-5 in North Indian Type 2 Diabetic Males and Its Correlation with Variables. J Clin Diagn Res., 2013, 7(12): 2936-2938.

36) Qiu X, Fandel TM, Lin G and et al.: Cavernous smooth muscle hyperplasia in a rat model of hyperlipidaemia-associated erectile dysfunction. British Journal of Urology International, 2011, 108 (11): 18661872.
37) Demir O, Murat N, Soner BC et al.: Acute effects of hypercholesterolemic diet on erectile responses in rats," Urologia Internationalis, 2010, 85 (1): 112-117.

38) Ahmed I, Aamir Au, Anwar E, Ali SS, Ali A, Ali A.: Erectile dysfunction and type 2 diabetes mellitus in northern Pakistan. J Pak Med Assoc., 2013, 63(12):1486-90.

39) Giugliano $F$, Maiorino $M$, Bellastella G, Gicchino $M$, Giugliano D and Esposito K.: Determinants of erectile dysfunction in type 2 diabetes. International Journal of Impotence Research, 2010, 22: 204-209.

40) Sharifi F, Asghari M, Jaberi Y, Salehi O, and Mirzamohammadi F.: Clinical Study: Independent Predictors of Erectile Dysfunction in Type 2 Diabetes Mellitus: Is It True What They Say about Risk Factors?. ISRN Endocrinology, 2012 (2012), Article ID 502353, 5 pages. http://dx.doi.org/10.5402/2012/502353 
Table (1a): Distribution of biomedical variable among study group.

\begin{tabular}{|c|c|c|}
\hline Biomedical variables & Categories & No. (\%) \\
\hline \multirow{4}{*}{ Age groups } & $30-40$ & $39(21.2)$ \\
\hline & $41-50$ & $27(14.7$ \\
\hline & $51-60$ & $104(56.5)$ \\
\hline & $>60$ & $14(7.6)$ \\
\hline \multirow[t]{4}{*}{ Educational levels } & illiterate & $13(7.1)$ \\
\hline & literate & $104(56.5)$ \\
\hline & secondary & $63(34.2)$ \\
\hline & university & $4(2.2)$ \\
\hline \multirow[t]{5}{*}{ BMI } & Average & $62(33.7)$ \\
\hline & overweight & $37(20.1)$ \\
\hline & mild obesity & $15(8.2)$ \\
\hline & moderate obesity & $67(36.4)$ \\
\hline & sever obesity & $3(1.6)$ \\
\hline \multirow{4}{*}{ Smoking condition } & non & $75(40.8)$ \\
\hline & passive & $88(47.8)$ \\
\hline & ex-smoker & $2(1.0)$ \\
\hline & current & $19(10.3)$ \\
\hline \multirow[t]{4}{*}{ Sport practice } & No & $163(88.6)$ \\
\hline & Imperfect & $16(8.7)$ \\
\hline & accepted & $3(1.6)$ \\
\hline & perfect & $2(1.1)$ \\
\hline \multirow[t]{2}{*}{ Blood pressure } & Normal & $122(66.3)$ \\
\hline & Hypertensive & $62(33.7)$ \\
\hline \multirow[t]{2}{*}{ Total cholesterol } & Normal & $147(79.8)$ \\
\hline & hypercholesterolemia & $37(20.2)$ \\
\hline \multirow[t]{2}{*}{ HDL } & Normal & $173(94.0)$ \\
\hline & Low & $11(6.0)$ \\
\hline
\end{tabular}

Table (1b): Distribution of biomedical variable among study group.

\begin{tabular}{|l|c|l|l|l|l|}
\hline Biomedical variables & $\mathrm{N}$ & Minimum & Maximum & Mean & Std. Deviation \\
\hline Age in years & 184 & 26.00 & 68.00 & 50.2500 & 9.44310 \\
\hline Systolic blood pressure mmHg & 184 & 110.00 & 170.00 & 129.3750 & 14.71090 \\
\hline Diastolic blood pressure in mmHg & 184 & 70.00 & 100.00 & 84.3750 & 9.83557 \\
\hline Fasting blood glucose mg/dL & 184 & 130.00 & 290.00 & 167.9348 & 28.53578 \\
\hline Total blood cholesterol mg/dL & 184 & 170.00 & 290.00 & 205.8967 & 42.49893 \\
\hline High density lipoprotein mg/dL & 184 & 33.00 & 55.00 & 48.8859 & 4.71633 \\
\hline Hb A1C & 184 & 6.50 & 11.20 & 7.6880 & 1.06805 \\
\hline Erectile function score & 184 & 7.00 & 25.00 & 19.4728 & 5.99538 \\
\hline
\end{tabular}


Table (2): Biomedical Risks of erectile dysfunction among study group.

\begin{tabular}{|c|c|c|c|c|c|c|c|}
\hline \multirow[t]{2}{*}{ Biomedical data } & \multirow[t]{2}{*}{ categories } & \multicolumn{3}{|c|}{ Erectile function } & \multirow{2}{*}{$\begin{array}{l}\text { Odds } \\
\text { ratio }\end{array}$} & \multicolumn{2}{|c|}{ Confidence I $(95 \%)$} \\
\hline & & Normal & dysfunction & Total & & lower & upper \\
\hline \multirow[t]{2}{*}{ Age groups } & $<50$ years & $66(100.0)$ & $0(0.0)$ & $66(100.0)$ & \multirow{2}{*}{$\begin{array}{l}X^{2}=77 \\
43^{*}\end{array}$} & & \\
\hline & $>50 y e a r s$ & $39(33.1)$ & $79(66.9)$ & $118(100.0)$ & & & \\
\hline \multirow[t]{2}{*}{ educational } & Illiterate and literate & $61(52.1)$ & $56(47.9)$ & $117(100.0)$ & \multirow[t]{2}{*}{0.569} & \multirow[t]{2}{*}{0.30} & \multirow[t]{2}{*}{1.06} \\
\hline & 2ry and university & $44(65.7)$ & $23(34.3)$ & $67(100.0)$ & & & \\
\hline \multirow[t]{2}{*}{ Smoking condition } & Non smokers & $103(62.4)$ & $62(37.6)$ & $165(100.0)$ & \multirow[t]{2}{*}{$14.12 *$} & \multirow[t]{2}{*}{3.15} & \multirow[t]{2}{*}{63.2} \\
\hline & smokers & $2(10.5)$ & $17(89.5)$ & $19(100.0)$ & & & \\
\hline \multirow[t]{2}{*}{ BMI } & normal & $60(96.8)$ & $2(3.2)$ & $62(100.0)$ & \multirow[t]{2}{*}{$51.33^{*}$} & \multirow[t]{2}{*}{11.96} & \multirow[t]{2}{*}{220.16} \\
\hline & Overweight and obese & $45(36.9)$ & $77(63.1)$ & $122(100.0)$ & & & \\
\hline \multirow[t]{2}{*}{ blood pressure } & normal & $103(84.4)$ & $19(15.6)$ & $122(100.0)$ & \multirow{2}{*}{$\begin{array}{l}162.63 \\
*\end{array}$} & \multirow[t]{2}{*}{36.60} & \multirow[t]{2}{*}{722.61} \\
\hline & Hypertensive & $2(3.2)$ & $60(96.8)$ & $62(100.0)$ & & & \\
\hline \multirow[t]{2}{*}{ Total cholesterol } & normal & $104(70.7)$ & $43(29.3)$ & $147(100.0)$ & \multirow[t]{2}{*}{$87.07 *$} & \multirow[t]{2}{*}{11.56} & \multirow[t]{2}{*}{655.39} \\
\hline & high & $1(2.7)$ & $36(97.3)$ & $37(100.0)$ & & & \\
\hline \multirow[t]{2}{*}{ HDL } & normal & $102(59.0)$ & $71(41.0)$ & $173(100.0)$ & \multirow[t]{2}{*}{3.83} & \multirow[t]{2}{*}{0.98} & \multirow[t]{2}{*}{14.94} \\
\hline & low & $3(27.3)$ & $8(72.7)$ & $11(100.0)$ & & & \\
\hline
\end{tabular}

NB. X2 was calculated in age group as Odd's ratio cannot calculated due to the presence of zero value.

*Statistically significant.

Table (3): predictors of erectile dysfunction among target group (step wise linear regression analysis)

\begin{tabular}{|l|c|c|c|c|c|}
\hline \multirow{2}{*}{ Predictors } & \multicolumn{2}{|c|}{$\begin{array}{c}\text { Unstandardized } \\
\text { Coefficients }\end{array}$} & $\begin{array}{c}\text { Standardized } \\
\text { Coefficients }\end{array}$ & \multirow{2}{*}{ P } & \\
\cline { 2 - 5 } & $\mathbf{B}$ & $\begin{array}{c}\text { Std. } \\
\text { Error }\end{array}$ & Beta & & \\
\hline (Constant) & 58.867 & .840 & & 70.092 & .000 \\
\hline Hb A1C & -4.145 & .165 & -.738 & -25.109 & .000 \\
\hline Smoking condition & -.995 & .151 & -.148 & -6.603 & .000 \\
\hline Age in years & -.059 & .015 & -.093 & -4.004 & .000 \\
\hline cholesterol & -.013 & .004 & -.095 & -3.623 & .000 \\
\hline Effect $=97.3$
\end{tabular}

Table (4): Linear correlation between erectile function score and some study biomedical data.

\begin{tabular}{|l|r|r|r|r|r|r|r|}
\hline $\begin{array}{l}\text { Linear } \\
\text { correlation }\end{array}$ & $\begin{array}{c}\text { Systolic } \\
\text { blood } \\
\text { pressure }\end{array}$ & $\begin{array}{c}\text { Diastolic } \\
\text { blood } \\
\text { pressure }\end{array}$ & $\begin{array}{c}\text { Fasting } \\
\text { blood } \\
\text { glucose }\end{array}$ & $\begin{array}{c}\text { Total } \\
\text { cholesterol }\end{array}$ & $\begin{array}{c}\text { High } \\
\text { density } \\
\text { lipoprotein }\end{array}$ & $\begin{array}{c}\text { Age in } \\
\text { years }\end{array}$ & Hb A1C \\
\hline $\mathrm{r}$ & $-.865^{* *}$ & $-.826^{* *}$ & -.094 & $-.764^{* *}$ & $.303^{* *}$ & $-.690^{* *}$ & $-.957^{* *}$ \\
\hline $\mathrm{p}$ & .000 & .000 & .205 & .000 & .000 & .000 & .000 \\
\hline
\end{tabular}

*Statistically significant 


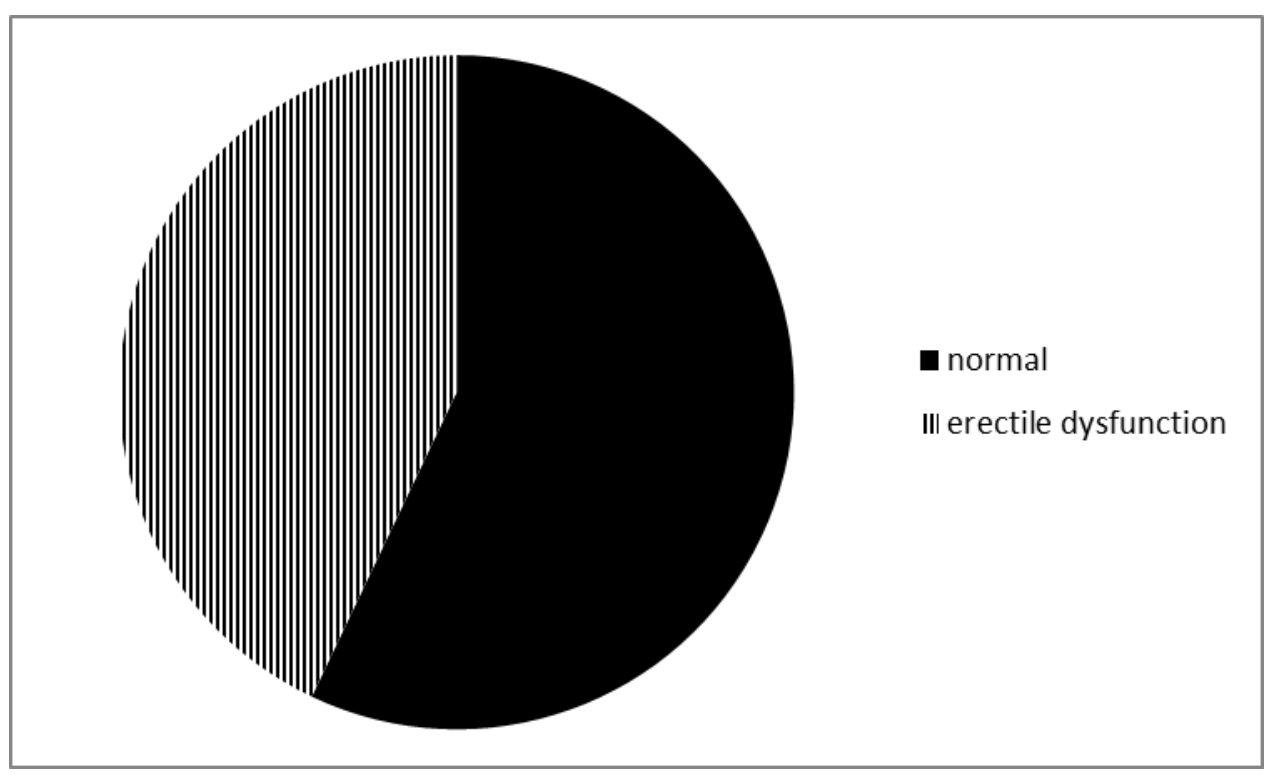

Figure (1): frequency of erectile dysfunction among study group.

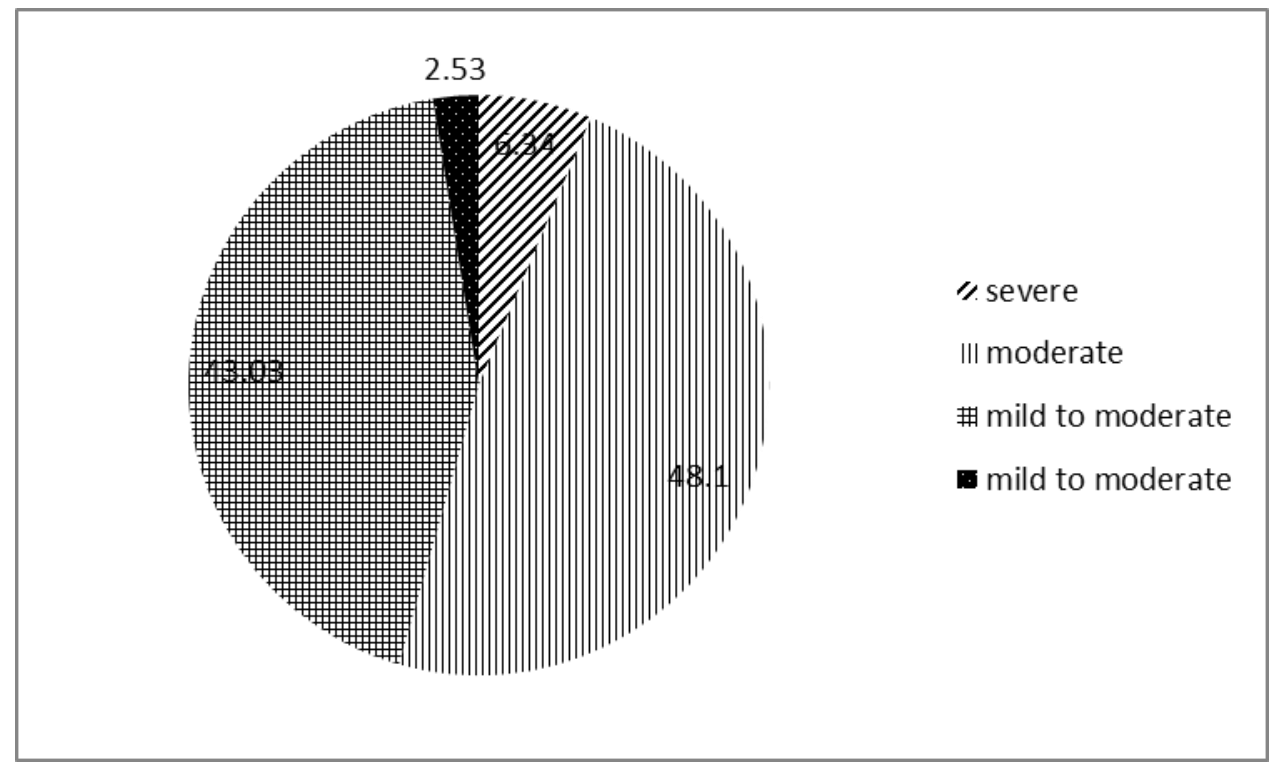

Figure (2): Distribution of erectile dysfunction grades 